\title{
Symptoms of titanium and nickel allergic sensitization in orthodontic treatment
}

\author{
Martina Zigante ${ }^{1^{*}}$ (D, Marijana Rincic Mlinaric ${ }^{2}$, Marija Kastelan ${ }^{3}$, Vjera Perkovic ${ }^{1}$, Magda Trinajstic Zrinski ${ }^{1}$ and \\ Stjepan Spalj ${ }^{1,4}$
}

\begin{abstract}
Aim: The study aimed to evaluate to which extent self-reported symptomatology, age, and sex are predictors of titanium and nickel allergic sensitization in patients in treatment with fixed orthodontic appliances.

Methods: The study analyzed 228 subjects aged 11-45 years (median 18, interquartile range 16-22); 68\% of them were females, and 52\% were adolescents. The allergic sensitization testing included epicutaneous patch test to titanium, titanium dioxide, titanium oxalate, titanium nitride, and nickel sulfate. The questionnaire on symptoms potentially linked to titanium and nickel sensitization was used.

Results: Prevalence of the allergic sensitization to titanium in patients undergoing orthodontic treatment was $4 \%$ ( $2 \%$ only to titanium without nickel) while to nickel $14 \%$ ( $12 \%$ nickel without titanium). Hypersensitivity to both metals at the same time was present in $2 \%$ of subjects. Sensitization to nickel was more common in females than in males (17 vs. $8 \%$ ) and much more common in adults than in adolescents with small effect size (20 vs. $8 \% ; p=$ 0.013). Sensitization to titanium was more common in females than in males (6 vs. 1\%) with no difference in age. Multiple logistic regression analysis revealed that adult age increases the odds for being sensitized to nickel for 2.4 $\times(95 \% \mathrm{Cl} 1.1-5.6 ; p=0.044)$ while watery eyes for $3.7 \times(95 \% \mathrm{Cl} 1.2-11.1 ; p=0.022)$. None of the symptoms were significant predictors of titanium sensitization.
\end{abstract}

Conclusion: Allergic sensitization to titanium and nickel are not very frequent in orthodontic patients, and selfreported symptomatology is a weak predictor of those sensitizations.

Keywords: Allergic sensitization, Hypersensitivity, Titanium, Nickel, Orthodontics

\section{Introduction}

Orthodontic treatment mostly implies fixed orthodontic appliance which consists of metal brackets bonded to tooth surface and archwire connecting them. Average treatment duration is between 2 and 3 years; therefore, safety and interactions of orthodontic materials with saliva, food, oral hygiene products, and oral and dental tissues should be kept in mind. Nickel- and titaniumcontaining alloys are often used in orthodontics. Nickel allotment in orthodontic alloys varies from $8 \%$ in stainless steel to $50 \%$ in nickel-titanium (NiTi) alloy [1].

\footnotetext{
* Correspondence: martina.zigante@uniri.hr

'Department of Orthodontics, University of Rijeka, Faculty of Dental

Medicine, Kresimirova 40, 51000 Rijeka, Croatia

Full list of author information is available at the end of the article
}

Titanium is also present in orthodontic appliances from $50 \%$ in $\mathrm{NiTi}$ alloys up to $80 \%$ in titanium-molybdenum alloy and $90 \%$ titanium-aluminum-vanadium alloy used for orthodontic mini implants.

Hypersensitivity is an excessive, inadequate reaction of the immune system to an otherwise harmless antigen [2]. Hypersensitivity reactions lead to tissue damage and can cause serious conditions and illnesses. Usually, they do not lead to symptomatic reactions at the first exposure, but upon re-exposure to the causative antigen [3]. The most common form of allergic reactions to dental biomaterials in the oral cavity is contact allergic reaction, late type of hypersensitivity reaction, or cell-mediated (type IV) hypersensitivity [4, 5]. Positive epicutaneous test signifies allergic sensitization while diagnosis of 
allergy can be established only when clinical signs are present and when removing of the allergen causes regression of symptoms.

Nickel is a metal widespread in the environment, an essential nutrient, but it is also a very common contact allergen [6]. Nickel allergy occurs more frequently than allergies to other metals altogether. The prevalence of nickel allergy has been estimated up to $28.5 \%$ of the general population and cannot be considered as low potential risk $[7,8]$.

Due to its high biocompatibility, titanium was previously considered to have no allergic potential; however, some authors report that titanium can be erosive if it co-exists with other types of metal or when it is exposed to fluoride ions in the acidic environment [9-11]. This suggests that during orthodontic treatment which includes presence of several types of metal alloys in the oral cavity media, such reactions may occur. There is also an increasing number of cases in which titanium allergy is reported in patients with implanted cardiac pacemaker, joint endoprosthesis, endovascular stents, surgical staples, and dental implants [12-16]. However, allergic sensitization to titanium alloys has not been systematically studied.

The aims of this study were to assess the prevalence of the allergic sensitization to titanium and nickel in patients undergoing orthodontic treatment with fixed appliances containing titanium and nickel and to evaluate to which extent self-reported symptomatology, age, and sex are related to them. Hypotheses of this study were that both titanium and nickel allergic sensitizations are more frequent in females and in adults and that a selfreported symptom of oral burning is the most powerful predictor of both sensitizations.

\section{Materials and methods}

A total of 250 subjects undergoing orthodontic treatment in three orthodontic offices in Croatia were asked to participate in this observational cross-sectional study. Assuming the prevalence of allergies of 15-20\% (95\% confidence intervals $10-25 \%$ ) and precision of $5 \%$ estimated, sample size was calculated to be $196-246$, so it was decided to recruit 250 participants. Inclusion criteria were treatment with fixed orthodontic appliance, while exclusion criteria were diabetes, endocrine and autoimmune diseases, and practicing water sports. All patients were treated with the same kind of metallic brackets (Ortho Classic, USA) and archwires (GAC International, Japan). Orthodontic forces were mild and continuous, part of the patients was in the phase of treatment involving intermaxillary elastics and in case of the space closure sliding mechanics was used. From a total of 250 subjects invited to participate, 22 (9\%) dropped out because of the practicing of water sports or uncomplete questionnaires on symptoms potentially linked to titanium and nickel allergies. Therefore, 228 participants were included in the study in the age of 11 to 45 years (median 18, interquartile range 16-22); $68 \%$ of them were females, and $52 \%$ were adolescents. None of the subjects with incomplete questionnaire on oral changes and symptoms potentially linked to titanium and nickel allergies were allergic to titanium nor to nickel.

Epicutaneous testing and administration of questionnaires were performed in the period from 2 months after bonding the appliance up to 24 months of treatment. In order to control and address potential sources of selection and recall bias, the same questionnaire form was applied and potential ambiguities were addressed the same way; it was explained that the testing is nothing scary or harmful; we asked participants not to overemphasize the self-reported symptoms, and we tried to keep track of the duration of orthodontic treatment, so the participants could remember if they experienced different symptoms since they had been treated with fixed orthodontic appliances in comparison with before the treatment. All participants were tested for allergic sensitization, and testing included the application of an epicutaneous patch test to nickel sulfate, titanium, titanium dioxide, titanium oxalate, and titanium nitride with petrolatum used as control (Chemotechnique Diagnostics, Vellinge, Sweden). The skin was cleaned by wiping with cotton wool soaked in medical petrol (Medimon, Split, Croatia) in order to degrease it. The allergens were applied on the upper arm skin and left under occlusion for 2 days, and the patients were instructed not to wet the area. Evaluations of the skin reactions were performed three times-on the second, fourth, and seventh day after applying the patches, as suggested by the manufacturer. Skin reactions were evaluated according to Reading Plate (Chemotechnique Diagnostics, Vellinge, Sweden).

The questionnaire on oral changes and symptoms potentially linked to titanium and nickel allergies was used. Closed type questions with dichotomous answers were applied, meaning that subject could choose between yes and no answer $(0=$ no; $1=$ yes $)$, whereas all questions were related to the period since the patient started the orthodontic treatment. Questionnaire for patient-reported symptoms related to the period of orthodontic treatment included questions on possible onset of the following symptoms: oral burning feeling, changed sense of taste, weak sense of taste, metal taste, lack of saliva, weak sense of smell, changed sense of smell, swollen tongue feeling, skin changes, swelling in the oral cavity or facial swelling, abdominal pain, diarrhea, bloating, frequent headaches, tinnitus, dizziness, nose leaking, watery eyes, 
and frequent sneezing. In case oral burning was a reported symptom, its intensity was evaluated by the visual analog scale where $0=$ no feeling of oral burning and $100=$ the strongest possible feeling of oral burning. Patients were determining the intensity of burning by placing a mark on a visual analog scale.

Prevalence of allergic sensitization was estimated with 95\% confidence intervals (CI) [17]. Predictors of allergies were explored by applying Fisher's exact test and logistic regression, and odds ratios (OR) with 95\% CI were calculated. Effect size for Fisher's test was quantified by means of Cramer V. For interpretation, the Cohen criteria were used $0.1-0.3=$ small, $0.3-0.5=$ medium, $0.5-0.7=$ large, and $>0.7$ very large effect size [18]. In the interpretation, $\mathrm{OR}=1.5$ was considered mild, while moderate $>3$, and large $>$ 9 [19]. All statistical analyses were performed in the statistical software IBM SPSS 22 (IBM Corp, Armonk, USA).

\section{Results}

Prevalence of the allergic sensitization to titanium and/ or nickel in patients undergoing orthodontic treatment was $16 \%$ (95\% CI $12-22 \%$ ), less often to titanium than nickel (4\%; 95\% CI 2-8\% vs 14\%; 95\% CI 10-19\%). Isolated sensitization on titanium (without nickel) was detected in $2 \%$ of subjects (95\% CI 1-5\%) while isolated sensitization on nickel (without titanium compounds) was detected in $12 \%$ of subjects ( $95 \%$ CI $8-17 \%$ ). Hypersensitivity to both metals at the same time was present in $2 \%$ of subjects (95\% CI $1-5 \%$ ). Females were more often sensitized to nickel than males (17 vs $8 \%$ ) and much more adults than adolescents with small effect size $(20$ vs $8 \% ; p=0.013 ; V=0.169$; OR $=2.8$; $95 \%$ CI $1.2-$ 6.1). A titanium sensitization was also more common in females than in males (6 vs. 1\%) but equal in adolescents and adults.

In univariate analyzes, allergic sensitization to titanium and/or nickel was related to female sex, adult age, self-

Table 1 Univariate predictors of nickel and/or titanium sensitization

\begin{tabular}{|c|c|c|c|c|c|c|c|}
\hline \multirow[t]{2}{*}{ Variable } & \multirow[t]{2}{*}{ Category } & & \multicolumn{2}{|c|}{ Sensitization } & \multirow[t]{2}{*}{$p^{*}$} & \multirow[t]{2}{*}{$V^{* *}$} & \multirow{2}{*}{$\begin{array}{l}\mathrm{OR}^{* * *}(95 \% \\
\mathrm{Cl})\end{array}$} \\
\hline & & & Absent & Present & & & \\
\hline \multirow[t]{4}{*}{ Sex } & Male (0) & $N$ & 66 & 6 & 0.033 & 0.145 & $2.7(1.1-6.9)$ \\
\hline & & $\%$ & $91.7 \%$ & $8.3 \%$ & & & \\
\hline & Female (1) & $N$ & 125 & 31 & & & \\
\hline & & $\%$ & $80.1 \%$ & $19.9 \%$ & & & \\
\hline \multirow[t]{4}{*}{ Age } & Adolescents (0) & $N$ & 106 & 13 & 0.030 & 0.150 & $2.3(1.1-4.8)$ \\
\hline & & $\%$ & $89.1 \%$ & $10.9 \%$ & & & \\
\hline & Adults (1) & $N$ & 85 & 24 & & & \\
\hline & & $\%$ & $78.0 \%$ & $22.0 \%$ & & & \\
\hline \multirow[t]{4}{*}{ Weakened sense of taste } & No $(0)$ & $N$ & 188 & 34 & 0.023 & 0.151 & $5.5(1.1-28.6)$ \\
\hline & & $\%$ & $84.7 \%$ & $15.3 \%$ & & & \\
\hline & Yes (1) & $N$ & 3 & 3 & & & \\
\hline & & $\%$ & $50.0 \%$ & $50.0 \%$ & & & \\
\hline \multirow[t]{4}{*}{ Weakened sense of smell } & No $(0)$ & $N$ & 189 & 34 & 0.031 & 0.178 & $8.3(1.3-51.8)$ \\
\hline & & $\%$ & $84.8 \%$ & $15.2 \%$ & & & \\
\hline & Yes (1) & $N$ & 2 & 3 & & & \\
\hline & & $\%$ & $40.0 \%$ & $60.0 \%$ & & & \\
\hline \multirow[t]{4}{*}{ Swelling of tongue and/or face } & No $(0)$ & N & 167 & 27 & 0.040 & 0.150 & $2.6(1.1-6.0)$ \\
\hline & & $\%$ & $86.1 \%$ & $13.9 \%$ & & & \\
\hline & Yes (1) & N & 24 & 10 & & & \\
\hline & & $\%$ & $70.6 \%$ & $29.4 \%$ & & & \\
\hline \multirow[t]{4}{*}{ Watery eyes } & No $(0)$ & N & 175 & 29 & 0.034 & 0.159 & $3.0(1.2-7.7)$ \\
\hline & & $\%$ & $85.8 \%$ & $14.2 \%$ & & & \\
\hline & Yes (1) & $N$ & 16 & 8 & & & \\
\hline & & $\%$ & $66.7 \%$ & $33.3 \%$ & & & \\
\hline
\end{tabular}


reported weak sense of taste, self-reported weak sense of smell, swelling of the tongue and/or face, and watery eyes (Table 1).

All predictors had small effect sizes; self-reported weak sense of taste and smell and watery eyes were moderate odds, while the rest of the predictors were mild odds. However, putting those predictors altogether in the logistic regression model in order to control their interrelationships, only sex and watery eyes remained significant. The odds are $2.7 \times$ higher that females will be allergically sensitized compared to males (95\% CI $1.1-6.9 ; p=0.043)$, while subjects with watery eyes have $3.1 \times$ higher odds of being sensitized (95\% CI 1.1-8.3; $p=0.028$ ).

When analyzed separately, only adult age and watery eyes were related to the allergic sensitization to nickel in univariate analyzes (Table 2).

When both predictors were put together in a logistic regression model, adult age decreased its odd for sensitization to nickel from 2.8 to 2.4 (95\% CI 1.15.6; $p=0.044)$, while self-reported watery eyes became an even more stronger predictor, increasing the odds from 3.0 to 3.7 (95\% CI 1.2-11.1; $p=0.022$ ).

Predictors of sensitization to titanium in univariate analyses were self-reported sense of oral burning, change of sense of taste, weakened sense of taste, weakened sense of smell, swelling of the tongue and/or face, and vertigo (Table 3).

However, in multiple logistic regression model, all predictors became insignificant.

Sneezing, rhinorrhea, headache, bloating, digestion problems and diarrhea, abdominal pain, dry mouth, metallic taste in the mouth, changes of the sense of smell, tinnitus, or skin changes were not related to the allergic sensitization to nickel, sensitization to titanium, nor to both of those metals.

\section{Discussion}

Based on the results of this study, allergic sensitizations to titanium and nickel in patients undergoing orthodontic treatment are not very frequent, with titanium sensitization less prevalent than nickel, and there are few typical symptoms accompanying them. Titanium sensitization is of special interest in orthodontics, since titanium brackets are considered as an alternative in patients with nickel hypersensitivity, which might not be safe considering that some patients with hypersensitivity on nickel are also sensitized on titanium. In case of patient medical history of nickel hypersensitivity, ceramic brackets might be safer alternative.

Until nowadays, considerations regarding oral dosage of metals or allergens generally leading to oral contact hypersensitivity outburst are not clarified. Considering the interval of treatment in which epicutaneous testing on titanium and nickel was performed, some patients were in the phase of treatment involving intermaxillary elastics. Intermaxillary elastics and application of higher forces can cause more cracking of the protective corrosion layer on the surface of the archwire leading to more pronounced discharge of its components in the oral cavity. However, in sensitized patients, such usage of intermaxillary elastics and application of higher forces could trigger allergic contact reaction outburst due to higher metal release.

Symptoms related to nickel or titanium allergic sensitization in univariate analyses of present research are a weak sense of smell and/or taste, swellings of the tongue or face, and watery eyes. Previous data also suggest that gustatory impairment, sensory dysfunctions, swelling of the lip and face, and even tongue may be the symptoms of oral contact allergy [20-23]. The orofacial region has been associated with type I, III, and IV allergies. Metals can be bonded with native proteins to form

Table 2 Univariate predictors of nickel sensitization

\begin{tabular}{|c|c|c|c|c|c|c|c|}
\hline \multirow[t]{2}{*}{ Variable } & \multirow[t]{2}{*}{ Category } & & \multicolumn{2}{|c|}{ Sensitization } & \multirow[t]{2}{*}{$p^{*}$} & \multirow[t]{2}{*}{$V^{* *}$} & \multirow{2}{*}{$\begin{array}{l}\mathrm{OR}^{* * *}(95 \% \\
\mathrm{Cl})\end{array}$} \\
\hline & & & Absent & Present & & & \\
\hline \multirow[t]{4}{*}{ Watery eyes } & No & $N$ & 179 & 25 & 0.033 & 0.149 & $3.0(1.1-7.8)$ \\
\hline & & $\%$ & $87.7 \%$ & $12.3 \%$ & & & \\
\hline & Yes & $N$ & 17 & 7 & & & \\
\hline & & $\%$ & $70.8 \%$ & $29.2 \%$ & & & \\
\hline \multirow[t]{4}{*}{ Age } & Adolescent & $N$ & 109 & 10 & 0.013 & 0.169 & $2.8(1.2-6.1)$ \\
\hline & & $\%$ & $91.6 \%$ & $8.4 \%$ & & & \\
\hline & Adult & $N$ & 87 & 22 & & & \\
\hline & & $\%$ & $79.8 \%$ & $20.2 \%$ & & & \\
\hline
\end{tabular}


Table 3 Univariate predictors of titanium sensitization

\begin{tabular}{|c|c|c|c|c|c|c|c|}
\hline \multirow[t]{2}{*}{ Variable } & \multirow[t]{2}{*}{ Category } & & \multicolumn{2}{|c|}{ Sensitization } & \multirow[t]{2}{*}{$p^{*}$} & \multirow[t]{2}{*}{$V^{* *}$} & \multirow[t]{2}{*}{$\mathrm{OR}^{* * *}(95 \% \mathrm{Cl})$} \\
\hline & & & Absent & Present & & & \\
\hline \multirow[t]{4}{*}{ Oral burning } & No $(0)$ & $N$ & 209 & 8 & 0.022 & 0.152 & $5.8(1.1-31.4)$ \\
\hline & & $\%$ & $96.3 \%$ & $3.7 \%$ & & & \\
\hline & Yes (1) & $N$ & 9 & 2 & & & \\
\hline & & $\%$ & $81.8 \%$ & $18.2 \%$ & & & \\
\hline \multirow[t]{4}{*}{ Changed sense of taste } & No $(0)$ & N & 203 & 7 & 0.035 & 0.176 & $5.8(1.4-24.7)$ \\
\hline & & $\%$ & $96.7 \%$ & $3.3 \%$ & & & \\
\hline & Yes (1) & N & 15 & 3 & & & \\
\hline & & $\%$ & $83.3 \%$ & $16.7 \%$ & & & \\
\hline \multirow[t]{4}{*}{ Weakened sense of taste } & No $(0)$ & N & 214 & 8 & 0.024 & 0.232 & $13.4(2.1-84.1)$ \\
\hline & & $\%$ & $96.4 \%$ & $3.6 \%$ & & & \\
\hline & Yes (1) & $N$ & 4 & 2 & & & \\
\hline & & $\%$ & $66.7 \%$ & $33.3 \%$ & & & \\
\hline \multirow[t]{4}{*}{ Weakened sense of smell } & No $(0)$ & $N$ & 215 & 8 & 0.016 & 0.260 & $17.9(2.6-122.6)$ \\
\hline & & $\%$ & $96.4 \%$ & $3.6 \%$ & & & \\
\hline & Yes (1) & N & 3 & 2 & & & \\
\hline & & $\%$ & $60.0 \%$ & $40.0 \%$ & & & \\
\hline \multirow[t]{4}{*}{ Swelling of tongue and/or face } & No $(0)$ & $N$ & 189 & 5 & 0.008 & 0.211 & $6.5(1.8-23.9)$ \\
\hline & & $\%$ & $97.4 \%$ & $2.6 \%$ & & & \\
\hline & Yes (1) & $N$ & 29 & 5 & & & \\
\hline & & $\%$ & $85.3 \%$ & $14.7 \%$ & & & \\
\hline \multirow[t]{4}{*}{ Vertigo } & No $(0)$ & $N$ & 210 & 7 & 0.008 & 0.252 & $11.3(2.5-51.7)$ \\
\hline & & $\%$ & $96.8 \%$ & $3.2 \%$ & & & \\
\hline & Yes (1) & N & 8 & 3 & & & \\
\hline & & $\%$ & $72.7 \%$ & $27.3 \%$ & & & \\
\hline
\end{tabular}

*Fisher's exact test.

**Effect size

***Odds ratio

haptenic antigens in their ionic form or can trigger degranulation of mast cells and basophils [24, 25]. Swelling of the tongue could be a manifestation of the type I allergy to metals, or it may be a subjective sensation of edema due to actual numbness of the tongue [26].

Nevertheless, when put together in multiple regression, our study showed that the symptom of watery eyes was the most important predictor of having allergic sensitization primarily related to nickel. So, by this statistical procedure, the effect of other variables was controlled for or was kept constant pointing to the most prominent symptom related to sensitization. Watery eyes were not described before in relation to nickel or titanium contact allergy. The allergic eye symptoms are mostly associated with atopy and type I hypersensitivity. Increase of lacrimation is among the symptoms of ocular allergic conjunctivitis. In the early phase, mast cells activate allergic inflammation, whereas in the late phase recruitment of inflammatory cells to the site of allergic inflammation occurs [27]. The exact pathological mechanism of how ingested nickel alone could provoke systemic symptoms remains unknown. It could be that sensitized subjects have immunological system more prone to other allergies as well so the symptomatology can be intertwined.

Several symptoms were related to allergic sensitization to titanium in univariate analyses, namely self-reported swelling of the tongue, change of sense of taste and smell, oral burning, and even vertigo. However, all predictors had small effect size and in multiple regression become insignificant, so they cannot be considered as reliable predictors of titanium allergic sensitization. One of the reasons is probably a small number of subjects with titanium allergic sensitization.

We did not confirm oral burning as a predictor of allergic sensitization, as expected, contrary to others [28]. It seems that oral burning is rather associated with nutritional deficiencies (iron, folic acid, vitamin B, or zinc), 
infection with Candida albicans, conditions such as diabetes mellitus or Sjögren syndrome or even psychological causes (e.g., depression, anxiety, somatoform disorders) more likely than with the allergy [29, 30]. Dry mouth can be an isolated symptom of oral contact allergy to nickel and other metals or a part of the oral burning syndrome and it can also appear in a more serious form of xerostomia [31, 32]. Our study did not show that dry mouth or oral burning could be the predictors of hypersensitivity probably due to its multifactorial background.

This study also did not relate sneezing, rhinorrhea, headache, bloating, digestion problems or diarrhea, abdominal pain, dry mouth, metallic taste in the mouth, changes in the sense of smell, tinnitus, or skin changes to nickel or titanium hypersensitivity. There are very few studies investigating these symptoms in the context of allergies to dental materials. Some authors reported sneezing as one of the respiratory manifestations of nickel allergy [33]. Rhinorrhea was not reported as a symptom of nickel nor of titanium allergy, but it was connected with an allergy to endodontic materials [34]. Literature suggests that metallic taste could be connected with nickel allergy [32, 35]. Tinnitus is reported as one of the possible symptoms of metal allergy, but to chromium [36].

Contrary to present research, some authors suggest that bloating, abdominal pain, digestion problems or diarrhea, and cutaneous changes can be systemic signs of nickel allergy associated with ingestion of nickel [31, 37]. Headaches are sometimes reported in subjects with oral contact allergy, namely to nickel, but they appear rarely and are not a specific sign of an allergy [31, 38].

Since this study was based on self-reported symptomatology, previous exposition to titanium and nickel from other sources (space maintainers, removable appliances, piercings, tattoos, etc.) was not taken into account. Sensitization in patients wearing other types of orthodontic appliances and mini implants should be investigated for titanium and nickel sensitizations. Also, immunohistochemical analyses of gingiva of sensitized patients and analyses of gingival crevicular fluid could shed new insights on these allergies.

\section{Conclusion}

Allergic sensitization to titanium occurs more often than expected and therefore should not be overlooked. However, it is more uncommon than sensitization to nickel and there are no clear symptoms related to allergic sensitization to titanium and nickel. Titanium allergy needs to be further investigated.

\section{Authors' contributions}

MZ tested the subjects for allergic sensitization and collected, systemized, and interpreted the data from the questionnaire on oral changes and symptoms potentially linked to titanium and nickel allergies and wrote the manuscript with the help and guidance of MRM, MK, VP, and MTZ. MRM tested part of the subjects for allergic sensitization and collected the data from the questionnaire on oral changes and symptoms potentially linked to titanium and nickel allergies. MK tested part of the subjects for allergic sensitization and evaluated the skin reactions. VP collected the data from the questionnaire on oral changes and symptoms potentially linked to titanium and nickel allergies. MTZ tested part of the subjects for allergic sensitization and collected the data from the questionnaire on oral changes and symptoms potentially linked to titanium and nickel allergies. SS designed the study, made statistical analysis, helped in interpretation of the results and revised the manuscript. All authors provided critical feedback, read, and approved the final manuscript.

\section{Funding}

This study was supported by the Croatian Science Foundation under the Grants HRZZ IMUNODENT IP-7500-09-2014 and DOK-09-2018. Funding source had no involvement in the design of the study, collection, analysis, and interpretation of the data nor in the writing of the manuscript.

\section{Availability of data and materials}

The datasets used and/or analyzed during the current study are available from the corresponding author on reasonable request.

\section{Ethics approval and consent to participate}

The study was performed according to Declaration of Helsinki 1964 and its later amendments. All participants signed written informed consent and Institution's Ethics Committee approved the study (No. 003-05/15-1119 and 003-08/15-01/24).

\section{Consent for publication}

Not applicable.

\section{Competing interests}

The authors declare that they have no competing interests.

\section{Author details}

${ }^{1}$ Department of Orthodontics, University of Rijeka, Faculty of Dental Medicine, Kresimirova 40, 51000 Rijeka, Croatia. ${ }^{2}$ Orthodontic Office Rincic Mlinaric, Katarine Zrinske 1, 23000 Zadar, Croatia. ${ }^{3}$ Department of Dermatovenereology, University of Rijeka, Faculty of Medicine, Brace Branchetta 20, 51000 Rijeka, Croatia. ${ }^{4}$ Department of Dental Medicine 1, J.J. Strossmayer University of Osijek, Faculty of Dental Medicine and Health, Crkvena 21, 31000 Osijek, Croatia.

Received: 16 March 2020 Accepted: 6 May 2020

Published online: 01 July 2020

\section{References}

1. Chakravarthi S, Padmanabhan S, Chitharanjan AB. Allergy and orthodontics. J Orthodont Sci. 2012;1:83-7. https://doi.org/10.4103/2278-0203.105871.

2. Roitt IM, Delves PJ. Essential immunology. 10th ed. London: Blackwell Science Ltd; 2001.

3. Janeway CA Jr, Travers P, Walport M, Shlomchik MJ. Immunobiology: the immune system in health and disease. 5th ed. New York: Garland Science; 2001.

4. Syed M, Chopra R, Sachdev V. Allergic reactions to dental materials - a systematic review. J Clin Diagn Res. 2015;9:4-9. https://doi.org/10.7860/ JCDR/2015/15640.6589.

5. Gölz L, Papageorgiou SN, Jäger A. Nickel hypersensitivity and orthodontic treatment: a systematic review and meta-analysis. Contact Dermatitis. 2015; 73:1-14. https://doi.org/10.1111/cod.12392.

6. Rizzi A, Nuncera E, Schiavino D. Metal allergy and tolerance development. In: Chen JK, Thyssen JP, editors. Metal allergy: from dermatitis to implant and device failure. 1st ed. Berlin: Springer; 2018.

7. Kuhta M, Pavlin D, Slaj M, Varga S, Lapter-Varga M, Slaj M. Type of archwire and level of acidity: effects on the release of metal ions from orthodontic appliances. Angle Orthod. 2009;79:102-10. https://doi.org/ 10.2319/083007-401.1. 
8. Hostynek JJ, Reagan KE, Maibach HI. Nickel allergic hypersensitivity: prevalence and incidence by country, gender, age and occupation. In: Hostynek JJ, Maibach HI, editors. Nickel and the skin. Absorption, immunology, epidemiology, and metallurgy. Bosa Raton: CRC Press; 2002.

9. Koike M, Fujii $\mathrm{H}$. In vitro assessment of corrosive properties of titanium as a biomaterial. J Oral Rehabil. 2001;28:540-8. https://doi.org/10.1046/j.13652842.2001.00690.x

10. Matono $Y$, Nakagawa M, Matsuya S, Ishikawa K, Terada Y. Corrosion behavior of pure titanium and titanium alloys in various concentrations of acidulated phosphate fluoride (APF) solutions. Dent Mater J. 2006;25:104-12. https:// doi.org/10.4012/dmj.25.104

11. Fragou S, Eliades T. Effect of topical fluoride application on titanium alloys: a review of effects and clinical implications. Pediatr Dent. 2010;32:99-105. 204 83011.

12. Siddiqi A, Payne AG, De Silva RK, Duncan WJ. Titanium allergy: could it affect dental implant integration? Clin Oral Implants Res. 2011;22:673-80. https://doi.org/10.1111/j.1600-0501.2010.02081.x

13. Müller K, Valentine-Thon E. Hypersensitivity to titanium: clinical and laboratory evidence. Neuro Endocrinol Lett. 2006:27:31-5. 17261997.

14. Schalock PC, Menné T, Johansen JD, Taylor JS, Maibach HI, Lidén C, et al. Hypersensitivity reactions to metallic implants - diagnostic algorithm and suggested patch test series for clinical use. Contact Dermatitis. 2012;66:4-19. https://doi.org/10.1111/j.1600-0536.2011.01971.x.

15. Hofmann SC, Plett M, Jansen S, Thomas P, Thölken KFM. Titanium hypersensitivity causing painful intra-abdominal oedema after staple-fixed inguinal hernia repair. Contact Dermatitis. 2018;79:48-9. https://doi.org/10. 1111/cod.12985

16. Hosoki M, Nishigawa K, Miyamoto Y, Ohe G, Matsuka Y. Allergic contact dermatitis caused by titanium screws and dental implants. J Prosthodont Res. 2016;60:213-9. https://doi.org/10.1016/j.jpor.2015.12.004.

17. Newcombe RG. Two-sided confidence intervals for the single proportion: comparison of seven methods. Stat Med. 1998;17:857-72. 10.1.1.408.7107.

18. Cohen J. A power primer. Psychol Bull. 1992;112:155-9. https://doi.org/10. 1037/0033-2909.112.1.155.

19. Cohen J. Statistical power analysis for the behavioral sciences. 2nd ed. Hillsdale: Lawrence Erlbaum Associates;1998.

20. Raap U, Stiesch M, Kapp A. Clinical symptoms and diagnostic workup of allergic reactions on the oral mucosa. Hautarzt. 2012;63:687-92. https://doi. org/10.1007/s00105-012-2353-8.

21. Papakonstantinou E, Raap U. Oral cavity and allergy: meeting the diagnostic and therapeutic challenge. Curr Oral Health Rep. 2016;3:347-55. https://doi. org/10.1007/s40496-016-0111-1.

22. Schultz JC, Connelly E, Glesne L, Warshaw EM. Cutaneous and oral eruption from oral exposure to nickel in dental braces. Dermatitis. 2004;15:154-7. https://doi.org/10.2310/6620.2004.04022.

23. Jungmann S, Laux P, Bauer TT, Jungnickel H, Schönfeld N, Luch A. From the tattoo studio to the emergency room. Dtsch Arztebl Int. 2016;113:672-5. https://doi.org/10.3238/arztebl.2016.0672.

24. Schramm M, Pitto RP. Clinical relevance of allergological tests in total hip joint replacement. In: Willmann G, Zweymuller K, editors. Bioceramics in hip joint replacement. New York: Thieme; 2000.

25. Hallab N, Merritt K, Jacobs JJ. Metal sensitivity in patients with orthopaedic implants. J Bone Joint Surg Am. 2001:83:428-36. https://doi.org/10.2106/ 00004623-200103000-00017.

26. Noble J, Ahing SI, Karaiskos NE, Wiltshire WA. Nickel allergy and orthodontics, a review and report of two cases. Br Dent J. 2008;204:297-300. https://doi.org/10.1038/bdj.2008.198.

27. Kari O, Saari KM. Updates in the treatment of ocular allergies. J Asthma Allergy. 2010;3:149-58. https://doi.org/10.2147/JAA.S13705.

28. Shelley BW. Gingival hyperplasia from dental braces. Cutis. 1981;28:149-50. 7285623.

29. Terai $H$, Shimahara M. Glossodynia from Candida-associated lesions, burning mouth syndrome, or mixed causes. Pain Med. 2010;11:856-60. https://doi. org/10.1111/j.1526-4637.2010.00861.x.

30. Jimson S, Rayesh E, Krupaa RJ, Kasthuri M. Burning mouth syndrome. J Pharm Bioallied Sci. 2015;7:194-6. https://doi.org/10.4103/0975-7406. 155899

31. Norwegian Board of Health. Use of dental materials in Norway. Oslo: Norwegian Board of Health; 1998. (No:IK-2652).

32. Muris J, Goossens A, Gonçalo M, Bircher AJ, Giménez-Arnau A, Foti C, et al. Sensitization to palladium and nickel in Europe and the relationship with oral disease and dental alloys. Contact Dermatitis. 2015;72:286-96. https:// doi.org/10.1111/cod.12327.

33. Brera S, Nicolini A. Respiratory manifestations due to nickel. Acta Otorhinolaryngol Ital. 2005;25:113-115. PMCID: PMC2639879.

34. Karabucak B, Stoopler ET. Root canal treatment on a patient with zinc oxide allergy: a case report. Int End J. 2007;40:800-7. https://doi.org/10.1111/j. 1365-2591.2007.01275.x

35. Stathopoulos IP, Andrianopoulos N, Paschaloglou D, Tsarouchas I. Revision total knee arthroplasty due to bone cement and metal hypersensitivity. Arch Orthop Trauma Surg. 2017;137:267-71. https://doi.org/10.1007/s00402016-2614-6.

36. Persson S, Gjerdet NR, Tornes K. Metal fragment in the temporomandibular joint: a case report. Int J Oral Maxillofac Surg. 2003;3:653-5. https://doi.org/ 10.1054/ijom.2002.0422.

37. Ricciardi L, Carni A, Loschiavo G, Gangemi S, Tigano V, Arena E, et al. Systemic nickel allergy: oral desensitization and possible role of cytokines interleukins 2 and 10. Int J Immunopathol Pharmacol. 2013;26:251-7. https://doi.org/10.1177/039463201302600127.

38. Lygre GB, Gjerdet NR, Grønningsaeter AG, Björman L. Reporting on adverse reactions to dental materials: intraoral observations at a clinical follow-up. Community Dent Oral Epidemiol. 2006;31:200-6. https://doi.org/10.1034/j. 1600-0528.2003.00037x.

\section{Publisher's Note}

Springer Nature remains neutral with regard to jurisdictional claims in published maps and institutional affiliations.

\section{Submit your manuscript to a SpringerOpen ${ }^{\circ}$ journal and benefit from:}

- Convenient online submission

- Rigorous peer review

- Open access: articles freely available online

- High visibility within the field

- Retaining the copyright to your article

Submit your next manuscript at $>$ springeropen.com 